gian mắc cận thị, mức độ cận thị, và chiêuu dài trục nhãn cầu có liên quan với tổn thương hắc võng mạc quanh đĩa thị.

Chiều dày lớp sợi thân kinh quanh đĩa thị ở mắt có tổn thương hắc võng mạc quanh đĩa thị mỏng hơn ở mắt không có tổn thương. Yếu tố mức độ cận thị có liên quan với chiều dày lớp sợi thần kinh quanh đĩa thị.

\section{TÀI LIÊU THAM KHẢO}

1. Holden BA, Fricke TR, Wilson DA, et al. Global Prevalence of Myopia and High Myopia and Temporal Trends from 2000 through 2050. Ophthalmology. 2016;123(5):1036-1042.

2. Ng DS, Cheung CYL, Luk FO, Lai TYY et al. Advances of optical coherence tomography in myopia and pathologic myopia, Eye (Lond). (2016) Jul;30(7):901-16

3. Wang C-Y, Zheng Y-F, Liu B, et al. Retinal Nerve Fiber Layer Thickness in Children: The Gobi
Desert Children Eye Study. Invest Ophthalmol Vis Sci. 2018;59(12):5285-5291.

4. Nguyễn Thanh Thủy. Nghiên cứu đăc điểm lâm sàng và cận lâm sàng của mắt cận thị cao tại bệnh viện mắt trung ương. Luận văn Thạc sĩ y học. Đại học Y Hà Nội; 2012.

5. Jonsson $\dot{O}$, Damji KF, Jonasson $F$, et al. Epidemiology of the optic nerve grey crescent in the Reykjavik Eye Study. $\mathrm{Br}$ J Ophthalmol. 2005;89(1):36-39.

6. Koh VT, Nah GK, Chang $L$, et al. Pathologic changes in highly myopic eyes of young males in Singapore. Ann Acad Med Singapore. 2013;42(5):216-224.

7. Đoàn Hương Giang. Đăc điểm lâm sàng cân thị cao ở trẻ em và kết quả chỉnh kính. Luận văn Thạc sĩ y học. Đai học Y Hà Nội; 2017

8. Chen $S$, Wang $B$, Dong $N$, Ren $X$, Zhang $T$, Xiao L. Macular measurements using spectraldomain optical coherence tomography in Chinese myopic children. Invest Ophthalmol Vis Sci. 2014;55(11):7410-7416.

\title{
CHI PHÍ TRỰC TIẾP ĐIỀU TRI UNG THƯ ĐẠI TRỰC TRÀNG TẠI VIÊ̂T NAM, NĂM 2019
}

\section{TÓM TẮT}

Mục tiêu: Nghiên cứu được thực hiện nhằm đo lường chi phí trực tiếp điều trị ung thư đại trực tràng tại Việt Nam năm 2019.Phương pháp nghiển cứu: Nighiên cứu mô tả cắt ngang, dựa trên hồi cứu số liêu từ hồ sơ thanh toán khi ra viện và phỏng vấn 89 người bênh ung thư đại trực tràng hoàn thành đợt điêu trị trong thời gian thu thập số liệu của nghiển cứu, từ tháng 12/2019 đến tháng 6/2020 tai bênh viện K Trung ương. Kết quả và kết luận: Trong đợt điều trị hiện tại, tổng chi phí trực tiếp vào khoảng 43.484.000 VNĐ với chi phí thấp nhất là 11.988.000 VNĐ và chi phí cao nhất là 138.378.000 VNĐ. Đối với tổng chi phí trong năm 2019, tổng chi phí trực tiếp trung bình lên đến 246.813.000 VNĐ với chi phí thấp nhất là 11.988.000 VNĐ và chi phí cao nhất là 1.881.409.000 VNĐ. Trong các nhóm chi phí, chi phí tiền túi hộ gia đình đều chiếm tỷ trọng lớn hơn.

Tư khoá: Chi phí điều trị trực tiếp, ung thư đại trực tràng, Việt Nam

\section{SUMMARY \\ DIRECT COST OF COLORECTAL CANCER TREATMENT IN VIETNAM, 2019 \\ Objective: To measure the direct cost of}

\footnotetext{
*Trường Đại học Y tế Công Cộng

Chịu trách nhiệm chính: Nguyễn Quỳnh Anh

Email: nqa@huph.edu.vn

Ngày nhận bài: 19.2.2021

Ngày phản biên khoa học: 25.3.2021

Ngày duyệt bài: 6.4 .2021
}

\section{Nguyễn Quỳnh Anh*, Nguyễn Thu Hà*}

colorectal cancer treatment in Vietnam in 2019. Methods: Cross-sectional descriptive study, based on retrospective billing data from hospital discharge records and interviews with 89 colorectal cancer patients who completed treatment during data collection of the study, from December 2019 to June 2020 at Vietnam National Cancer Hospital. Results and conclusions: During the current treatment, the total direct cost was about 43,484,000 VND with the lowest cost of $11,988,000 \mathrm{VND}$ and the highest cost of $138,378,000$ VND. For total costs in 2019, the average total direct costs amount to VND 246,813,000 with the lowest cost of VND $11,988,000$ and the highest cost of VND 1,881,409,000. Among the cost groups, household out-of-pocket expenses accounted for a larger share.

Keywords; Direct treatment costs, colorectal cancer, Vietnam

\section{I. Đă̆T VẤN ĐỀ}

Mặc dù Việt Nam thuộc nhóm các quốc gia có thu nhập trung bình thấp, mô hình bệnh tật của Việt Nam lại có xu hướng tương tự như các quốc gia có thu nhập cao và thu nhập trung bình cao. Cụ thể, gánh nặng bệnh tật gầy ra bởi các bệnh không truyền nhiểm mà đặc biệt là các bệnh tim mạch và ung thư chiếm một tỷ trọng tăng dần trong cơ cấu bệnh tật. Gánh nặng bệnh tật của ung thư, đo lường thông qua giá trị số năm sống điều chỉnh theo mức độ tàn tật (Disability Adjusted Life Year, DALY), có xu hướng gia tăng trong giai đoạn 2008 - 2017. Cụ thể tổng DALY 
của nhóm bênh ung thư cho tất cả các nhóm tuổi tăng $31,5 \%$ trong giai đoạn này $(1,2,3)$.

Cùng với sự phát triển nhanh của kinh tế xã hội, công nghể y tế và tiến bộ y học trong điều trị ung thư chính là sự gia tăng chi phí của các công nghệ này. Tại Việt Nam, giá dịch vụ khám bệnh, chữa bệnh đã có những thay đổi nhất định, đặc biệt cùng với sự áp dụng của Thông tư 15/2018/TT-BYT, thông tư 37/2018/TT-BYT và Thông tư 39/2018/TT-BYT. Vì những lý do trên, nhằm cung cấp những bằng chứng đáng tin cậy giúp huy động và phân bổ nguồn lực trong kiểm soát ung thư cũng như làm tiền đề cho các nghiên cứu về kinh tế y tế trong thời gian tới, nhóm nghiên cứu tiến hành đề tài nghiên cứu "Đo lường chi phí điều trị trức tiếp của ung thư' đại trực tràng tại Việt Nam năm 2019".

\section{II. ĐỐI TƯợNG VÀ PHƯƠNG PHÁP NGHIÊN CỨU}

Thiết kế nghiên cứu: Nghiên cứu cắt ngang sử dụng số liệu định lượng

Đối tượng nghiên cứu: Được chẩn đoán mắc ung thư đại trực tràng (Colorectum Cancer, C18-C21), tại thời điểm tiến hành phỏng vấn, người bệnh được chỉ định là đã hoàn thành đợt điêu trị hiện tại

Thời gian và địa điểm nghiên cứu: từ tháng 12/2019 đến tháng 6/2020 tại bệnh viện $\mathrm{K}$ Trung Ương.

Cõ̃ mẫu: Áp dụng công thức tính cõ̃ mẫu ước lượng giá trị trung bình

$$
\mathrm{N}=\frac{z_{1-\infty / 2}^{2} \sigma^{2}}{\varepsilon^{2} \mu^{2}}
$$

$\mathrm{N}$ : Là số đối tượng cần điều tra, Z: Hê số tin cậy (Với độ tin cậy $95 \%$ thì giá trị của $Z=1,96$ ), б: Giá trị ước lượng của độ lệch chuẩn của đặc tính nghiên cứu trong quần thể, $\varepsilon$ : Độ chính xác tương đối, $\mu$ : Giá trị trung bình của đặc tính nghiên cứu trong quần thể

Sử dụng số liệu của bệnh ung thư đại trực tràng trong nghiển cứu khác (4) với $\mu=223$ triệu đồng và $\sigma=209$ triệu đồng; lây $\varepsilon=0,2$ thì số lượng người bệnh ung thư cần thiết đưa vào nghiên cứu ước tính cho nhóm bệnh ung thư đại trực tràng là $\mathrm{N}=85$. Thực tế thu thập được số liệu trên 89 người bệnh.

Phương pháp thu thập số liệu: Sử dụng Bảng hỏi có cấu trúc để phỏng vấn toàn bộ người bênh ung thư thỏa mãn tiêu chí nghiên cứu chuẩn bị ra viện vào thời điểm diễn ra nghiên cứu, Bảng kiểm có sẵn để thu thập thông tin liên quan đến số lượng dịch vụ sử dụng và chi phí điều trị của người bệnh được thu thập từ phiếu thanh toán ra viện của bệnh nhân. Các nhóm chi phí được thu thập bao gồm: C1 - Chi phí trực tiếp dành cho y tế - từ phía CSYT/Chính phủ, C2 - Chi phí trực tiếp dành cho y tế - từ phía người bệnh/BHYT, C3 Chi phí trực tiếp không dành cho y tế - từ phía người bệnh, C4 - Chi phí trực tiếp không dành cho y tế - từ phía gia đình.

Quản lý và phân tích số liệu: Số liệu được nhập bằng phần mềm Excel 2007 cho phần thông tin liên quan đến bệnh viện và phần mềm Epi data 3.1 cho các thông tin liên quan đến người bệnh.

Đạo đức nghiên cứu: Nghiên cứu tuân thủ quy trình xét duyệt của Hội đồng nghiên cứu khoa học Trường Đại học $Y$ tế công cộng.

\section{KẾT QUẢ NGHIÊN CỨU}

1. Các thông tin chung của đối tượng nghiên cứu

Bảng 1: Mô tả các thông tin cơ bản về người bệnh tham gia trả lời phỏng vấn

\begin{tabular}{|c|c|c|}
\hline Đặc điểm & $\begin{array}{c}\text { Tân } \\
\text { số (n) }\end{array}$ & $\begin{array}{c}\text { Tỷ lệ } \\
\text { (\%) }\end{array}$ \\
\hline \multicolumn{3}{|c|}{ Nhóm tuối } \\
\hline $15-30$ & 3 & $3,4 \%$ \\
\hline $31-45$ & 14 & $15,7 \%$ \\
\hline $46-60$ & 40 & $44,9 \%$ \\
\hline$>60$ & 32 & $36,0 \%$ \\
\hline \multicolumn{3}{|c|}{ Giới tính } \\
\hline Nữ & 65 & $73,0 \%$ \\
\hline Nam & 24 & $27,0 \%$ \\
\hline Tình trạng hôn nhân \\
\hline Chưa kết hôn & 3 & $3,4 \%$ \\
\hline Đã kết hôn & 81 & $91,0 \%$ \\
\hline Góa & 5 & $5,6 \%$ \\
\hline Ly dị/ly thân & 0 & $0 \%$ \\
\hline \multicolumn{2}{|c|}{ Trinh aô hoc vân } \\
\hline
\end{tabular}

\begin{tabular}{|c|c|c|}
\hline \multicolumn{3}{|c|}{ Trình độ học vấn } \\
\hline Chưa hết tiếu học & 18 & $20,2 \%$ \\
\hline Hết tiếu học & 26 & $29,2 \%$ \\
\hline Hết trung học cơ sở & 21 & $23,6 \%$ \\
\hline Hết trung học phố thông & 15 & $16,9 \%$ \\
\hline Cao đắng, trung cấp nghề & 5 & $5,6 \%$ \\
\hline Đaại học và trên đại học & 4 & $4,5 \%$ \\
\hline \multicolumn{2}{|c|}{ Tình trạng làm việc hiện tại } \\
\hline Thất nghiệp/khồng làm việc & 34 & $38,2 \%$ \\
\hline Hưu trí & 19 & $21,3 \%$ \\
\hline Đang có việc làm & 36 & $40,4 \%$ \\
\hline BHYT & \multicolumn{1}{c|}{} \\
\hline Không & 1 & $1,1 \%$ \\
\hline Có & 88 & $98,9 \%$ \\
\hline Cón
\end{tabular}

Tổng số người bệnh ung thư đại trực tràng tham gia trả lời phỏng vấn là 89 người bệnh. Về độ tuổi, độ tuổi trung bình của người bệnh tham gia phỏng vấn là $55,5( \pm 13,1)$ với độ tuổi thấp nhất là 15 tuổi và độ tuổi cao nhất là 80 tuổi, 
người bệnh nữ chiếm đa số $(73,0 \%)$. Đồng thời, đa số người bệnh tham gia trả lời phỏng vấn đã kết hôn (91,0\%).

Thu nhập hộ gia đình của nhóm người bệnh ung thư đại trực tràng khá thấp (85.500.000 đồng/năm). Số ngày điêu trị trung bình là 98,8 ngày dao động từ 5 đến 365 ngày.

2. Chi phí điêu tri ung thư đại trực tràng. Bảng 2 mô tả chi phí trung bình của người bệnh ung thư đại trực tràng trong nghiên cứu. Trong đợt điều trị hiện tại, tổng chi phí trực tiếp vào khoảng 43.484.000 VND với chi phí thấp nhất là 11.988 .000 VNĐ và chi phí cao nhất là 138.378.000 VNĐ. Giá trị Q1 là 26.987.000 VNĐ, chi phí trung vị cho đợt điều trị hiện tại là 35.006.000 VND và giá trị Q3 tương ứng là 56.016.000 VND.

Bảng 2: Chi phí trung bình của người bệnh ung thư đại trực tràng trong nghiên cứu Đơn vị tính: $1.000 \mathrm{VNO}$

\begin{tabular}{|c|c|c|c|c|c|c|c|}
\hline & Mean & SD & Min & Q1 & Median & Q3 & Max \\
\hline \multicolumn{7}{|c|}{ Chi phí cho đợt điều trị hiện tại } \\
\hline Chi tiền túi hộ gia đình & 20.311 & 14.862 & 625 & 9.367 & 17.324 & 26.554 & 78.206 \\
\hline Chi phí BHYT & 23.173 & 16.309 & 3.033 & 13.373 & 17.219 & 25.161 & 75.296 \\
\hline Tống chi trực tiếp & 43.484 & 24.243 & 11.988 & 26.987 & 35.006 & 56.016 & 138.378 \\
\hline \multicolumn{7}{|c|}{ Tống chi phí trong năm 2019 } \\
\hline Chi tiền túi hộ gia đình & 142.302 & 259.783 & 1.440 & 25.260 & 83.380 & 134.930 & 1.578 .568 \\
\hline Chi phí BHYT & 104.511 & 166.423 & 3.927 & 29.755 & 66.520 & 113.388 & 1.368 .056 \\
\hline Tống chi trực tiếp & 246.813 & 334.571 & 11.988 & 93.282 & 166.047 & 229.707 & 1.881 .409 \\
\hline
\end{tabular}

Đối với tổng chi phí trong năm 2019, tổng chi phí trực tiếp trung bình lên đến 246.813.000 VNĐ với chi phí thấp nhất là 11.988 .000 VNĐ và chi phí cao nhất là 1.881.409.000 VNĐ. Giá trị Q1 là 93.282.000 VNĐ, chi phí trung vị cho đợt điều trị hiện tại là 166.047.000 VNĐ và giá trị Q3 tương ứng là 229.707.000 VND.

Hình 1 minh họa các cấu phần chi phí trong tổng chi phí cho đợt điều trị hiện tại và tổng chi phí trong năm 2019. Trong đó tổng chi phí trong năm 2019 lớn gấp 5,7 lần so với chi phí của đợt điều trị hiện tại. Trong các nhóm chi phí, chi phí tiền túi hộ gia đình đều chiếm tỷ trọng lớn hơn. Cụ thể, đối với chi phí cho đợt điêu trị hiện tại, chi phí tiền túi hộ gia đình và chi phí từ phía BHYT lần lượt chiếm $46,7 \%$ và $53,3 \%$. Đối với chi phí trong năm 2019, chi phí tiên túi hộ gia đình và chi phí từ phía BHYT lần lượt chiếm $57,7 \%$ và $42,3 \%$.

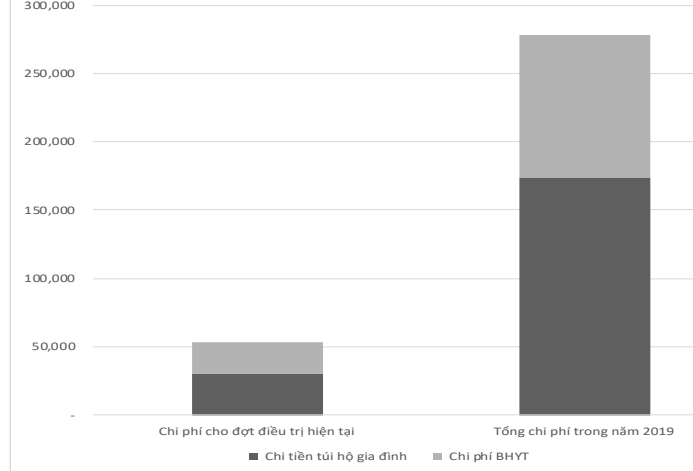

Hình 1: Tỷ lệ các nhóm chi phí của người bệnh ung thư đại trực tràng

Bảng 3: Tỷ lệ các nhóm chi phí của người bệnh ung thư đại trực tràng trong nghiên cứu phân theo lần nhập viện điều trị

\begin{tabular}{|c|c|c|c|c|}
\hline & $\begin{array}{c}\text { Chi phí trung } \\
\text { bình }\end{array}$ & Tỷ lệ \% & LCI & HCI \\
\hline Điều trị lần đâu & & & & \\
\hline Chi phí cho đợt điều trị hiện tại & & & & \\
\hline Chi tiền túi hộ gia đình & 21.274 & $34,7 \%$ & 14.676 & 27.872 \\
\hline Chi phí BHYT & 40.008 & $65,3 \%$ & 33.016 & 46.999 \\
\hline Tống chi trực tiếp & 61.283 & $100,0 \%$ & 49.850 & 72.715 \\
\hline Tống chi phí trong năm 2019 & & & & \\
\hline Chi tiền túi hộ gia đình & 140.217 & $56,9 \%$ & 30.355 & 250.078 \\
\hline Chi phí BHYT & 106.097 & $43,1 \%$ & 62.230 & 149.963 \\
\hline Tống chi trực tiếp & 246.314 & $100,0 \%$ & 101.515 & 391.113 \\
\hline Điêu trị tái phát & & & & \\
\hline Chi phí cho đợt điều trị hiện tại & & & & \\
\hline
\end{tabular}


VIETNAM MEDICAL JOURNAL N²2 - APRIL - 2021

\begin{tabular}{|c|c|c|c|c|}
\hline Chi tiền túi hộ gia đình & 16.023 & $49,3 \%$ & 10.770 & 21.277 \\
\hline Chi phí BHYT & 16.452 & $50,7 \%$ & 14.538 & 18.364 \\
\hline Tống chi trực tiếp & 32.475 & $100,0 \%$ & 26.276 & 38.673 \\
\hline Tống chi phí trong năm 2019 & & & & \\
\hline Chi tiền túi hộ gia đình & 106.359 & $45,8 \%$ & 43.976 & 168.741 \\
\hline Chi phí BHYT & 125.677 & $54,2 \%$ & 29.950 & 221.403 \\
\hline Tống chi trực tiếp & 232.036 & $100,0 \%$ & 114.994 & 349.077 \\
\hline Điêuu trị giai đoạn cuối & & & & \\
\hline Chi phí cho đợt điều trị hiện tại & & & & \\
\hline Chi tiền túi hộ gia đình & 23.666 & $63,5 \%$ & 19.089 & 28.244 \\
\hline Chi phí BHYT & 13.621 & $36,5 \%$ & 11.572 & 15.670 \\
\hline Tống chi trực tiếp & 37.288 & $100,0 \%$ & 32.657 & 41.918 \\
\hline Tống chi phí trong năm 2019 & & & & \\
\hline Chi tiền túi hộ gia đình & 180.261 & $68,8 \%$ & 66.078 & 294.444 \\
\hline Chi phí BHYT & 81.811 & $31,2 \%$ & 56.804 & 106.816 \\
\hline Tống chi trực tiếp & 262.071 & $100,0 \%$ & 143.372 & 380.769 \\
\hline
\end{tabular}

Bảng 3 mô tả giá trị 95\% khoảng tin cậy của tổng chi phí trực tiếp năm 2019 của người bệnh ung thư đại trực tràng phân theo lần nhập viện điều trị. Với người bệnh nhập viện điêuu trị lần đầu, trung bình của tổng chi phí trực tiếp của đợt điều trị hiên tai là 61.283 .000 đồng, $95 \%$ CI dao động từ 49.850.000 đồng đến 72.715.000 đồng. Chi phí tiền túi hô gia đình trong đợt điều trị hiện tại trung bình là 21.274.000 đồng, $95 \%$ CI dao đông từ 14.676 .000 đồng đến 27.872.000 đồng. Chi phí từ phía BHYT trong đợt điều trị hiện tai trung bình là 40.008 .000 đồng, $95 \% \mathrm{CI}$ dao động từ 33.016 .000 đồng đến 46.999 .000 đồng. Đối với tổng chi phí trong năm 2019 , tổng chi phí trực tiếp là 246.314.000 đồng và $95 \%$ khoảng tin cậy của tổng chi phí trực tiếp rơi vào khoảng từ 101.515 .000 đồng đến 391.113 .000 đồng. Chi phí trung bình và $95 \% \mathrm{CI}$ của chi tiền túi hộ gia đình là 140.217 .000 đồng (95\%CI: 30.355 .000 - 250.078.000 đồng). Tương tự đối với chi phí từ phía bảo hiểm y tế có tổng chi phí và $95 \%$ CI là 106.097.000 đồng (95\%CI: 62.230 .000 - 149.963.000 đồng).

Với người bệnh nhập viện điêu trị tái phát, trung bình của tổng chi phí trực tiếp của đợt điều trị hiện tại là 32.475 .000 đồng, $95 \%$ CI dao động từ 26.276.000 đồng đến 38.673.000 đồng. Chi phí tiền túi hộ gia đình trong đợt điều trị hiện tại trung bình là 16.023 .000 đồng, $95 \%$ CI dao động từ 10.770 .000 đồng đến 21.277.000 đồng. Chi phí từ phía BHYT trong đợt điều trị hiện tại trung bình là 16.452 .000 đồng, $95 \%$ CI dao động từ 14.538 .000 đồng đến 18.364 .000 đồng. Đối với tổng chi phí trong năm 2019, 95\% khoảng tin cậy của tổng chi phí trực tiếp rơi vào khoảng từ 114.994 .000 đồng đến 349.077 .000 đồng. Trong đó, 95\% khoảng tin cậy của chi phí tiền túi hộ gia đình là 29.950.000 - 221.403.000 đồng. Tướng tự đối với chi phí từ phía bảo hiểm y tế có $95 \%$ CI là 26.276.000 38.673.000 đồng.

Với người bệnh nhập viện điêu trị giai đoạn cuối trung bình của tổng chi phí trực tiếp của đợt điều trị hiện tại là 37.288 .000 đồng, $95 \%$ CI dao đồng từ $32.657 .000 \quad 41.918 .000$ đồng. Chi phí tiền túi hộ gia đình trong đợt điều trị hiện tại trung bình là 23.666.000 đồng, 95\%CI dao động từ 19.089.000 - 28.244.000 đồng. Chi phí từ phía BHYT trong đợt điều tri hiện tại trung bình là 13.621 .000 đồng, $95 \% \mathrm{CI}$ dao động từ 11.572.000 - 15.670.000 đồng. Đối với tổng chi phí trong năm 2019, 95\% khoảng tin cậy của tổng chi phí trực tiếp rơi vào khoảng từ 143.372.000 - 380.769.000 đồng. Trong đó, 95\% khoảng tin cậy của chi phí tiền túi hộ gia đình là 66.078 .000 - 294.444.000 đồng. Tương tự đối với chi phí từ phía bảo hiểm y tể có $95 \%$ CI là 32.657.000 - 41.918.000 đồng.

\section{BÀN LUẬN}

Trong đợt điều tri hiên tai, tổng chi phí trực tiếp vào khoảng 43.484.000 VNĐ với chi phí thấp nhất là $11.988 .000 \mathrm{VND}$ và chi phí cao nhất là 138.378.000 VNĐ. Đối với tổng chi phí trong năm 2019, tổng chi phí trực tiếp trung bình lên đến 246.813.000 VNĐ với chi phí thấp nhất là 11.988.000VNĐ và chi phí cao nhất là 1.881.409.000VNĐ. Trong các nhóm chi phí, chi phí tiền túi hộ gia đình đều chiếm tỷ trọng lớn hơn. Nghiên cứu chi phí bệnh tật của ung thư được thực hiện nhiều tại các nước phát triển, đặc biệt là Mỹ். Một nghiên cứu gần đây tại Mỹ (5) đã ước tính tổng chi phí y tế trên quy mô quốc gia cho 13 nhóm bệnh ung thư ở nam giới 
và 16 nhóm bệnh ung thư ở nữ giới trong năm 2010 và dự báo tổng chi phí vào năm 2020, dựa trên các số liệu cập nhật nhất về tỷ lệ mới mắc, tỷ lệ sống sót và chi phí y tễ. Trong đó, chi phí y tế của ung thư vú (nữ giới) là cao nhất (16.50 tỷ đôla $M y ̃)$, tiếp đến là ung thư đại trực tràng (14.14 tỳ đôla Mỹ), ung thư hạch (12.14 tỷ đôla Mỹ), ung thư phổi (12.12 tỷ đôla Mỹ) và ung thư tuyến tiên liệt (11.85 tỷ đôla Mỹ). Tại Việt Nam, nghiên cứu Đánh giá gánh nặng kinh tế của một số bệnh ung thư phổ biến được thực hiện từ năm 2012 (4). Với góc độ tính toán chi phí từ cả phía chính phủ và hộ gia đình, nghiên cứu đề cập một cách toàn diện tất cả các nhóm chi phí bao gồm: (1) chi phí trực tiếp dành cho y tế; (2) chi phí gián tiếp dành cho y tế; (3) chi phí trực tiếp không dành cho y tế; (4) Chi phí gián tiếp không dành cho y tế; (5) Chi phí cơ hội do giảm năng suất lao động và (6) Chi phí cơ hội do tử vong sớm. Kết quả nghiên cứu cho thấy, ung thư đại trực tràng có chi phí điều trị trung bình trong nằm 2012 là 154.270 .000 VND $(95 \% \mathrm{CI}$ : 137.803.000 VNĐ - 170.736.000 VNĐ). Cùng với lộ trình tính toán chi phí đầy đủ, trong nghiên cứu này, chúng tôi giả định rằng đa số chi phí từ góc độ cơ sở y tế đã được hạch toán đầy đủ trong giá phản ánh trong chi phí bảo hiểm y tế chi trả hoặc chi phí viện phí do người bệnh đồng chi trả và chi trả dịch vụ. Việc sử dụng giả định này có thể khiến cho tổng gánh nặng kinh tế trong nghiên cứu này có thể thấp hơn tổng gánh nặng kinh tế trên thực tế.

\section{KẾT LUÂN}

Trong đợt điều trị hiện tại, tổng chi phí trực tiếp vào khoảng 43.484.000 VND với chi phí thấp nhất là $11.988 .000 \mathrm{VNĐ}$ và chi phí cao nhất là 138.378.000 VNĐ. Đối với tổng chi phí trong năm 2019, tổng chi phí trực tiếp trung bình lên đến 246.813.000 VNĐ với chi phí thấp nhất là 11.988.000VNĐ và chi phí cao nhất là 1.881.409.000 VNĐ. Trong các nhóm chi phí, chi phí tiền túi hộ gia đình đều chiếm tỷ trọng lớn hơn.

\section{TÀI LIỆU THAM KHẢO}

1. Nguyễn Thanh Hương và cộng sự Báo cáo đề tài cấp bộ: Tuổi thọ khỏe mạnh và gánh nặng bệnh tật tại Việt Nam năm 2015, Hà Nội.

2. Nguyễn Thanh Hương và cộng sự Báo cáo đề tài cấp bộ: Tuổi thọ khỏe mạnh vgánh nặng bệnh tật tại Việt Nam năm 2015, Hà Nội.

3. Nguyễn Thị Trang Nhung, Trần Khánh Long, Bùi Ngọc Linh và cộng sứ. (2010), Gánh nặng bệnh tật và chấn thương ở Việt Nam, Nhà xuất bản y học, Hà Nội.

4. Nguyễn Quỳnh Anh và Nguyễn Thu Hà (2014), Báo cáo đề tài nghiên cứu cấp cơ sở: Gánh nắng kinh tế của 6 bệnh ung thư phố biến tai Việt Nam, .

5. Mariotto A.B., Robin Yabroff K., Shao Y. và cộng sự. (2011). Projections of the cost of cancer care in the United States: 2010-2020. J Natl Cancer Inst, 103(2), 117-128.

\section{GIÁ TRI CỦA THANG ĐIỂM HACOR ĐỂ DỰ ĐOÁN KẾT QUẢ CỦA THỞ MÁY KHÔNG XÂM NHẬP TRÊN BỆNH NHÂN ĐợT CẤP COPD}

\section{TÓM TẮT}

Mục tiêu: Đánh giá giá trị thang điểm HACOR trong dự đoán kết quả của thở máy không xâm nhập (TMKXN) ở bệnh nhân đợt cấp COPD. Phương pháp: Nghiên cứu mô tả hồi cứu đánh giá giá trị thang điểm HACOR để dự đoán kết quả của TMKXN trên 71 bệnh nhân đợt cấp COPD điêuu trị tại khoa Cấp cứu bệnh

\footnotetext{
${ }^{1}$ Trung tâm cấp cứu A9-Bênh viện Bạch Mai

2Trung tâm Chông độc - Bệnh viện Bạch Mai

${ }^{3}$ Bệnh viện đa khoa Quốc tế VINMEC

Chịu trách nhiệm chính: Đỗ Ngọc Sơn

Email: sonngocdo@gmail.com

Ngày nhận bài: 24.2.2021

Ngày phản biện khoa học: 29.3.2021

Ngày duyệt bài: 9.4.2021
}

Đỗ Ngọc Sơnn' ${ }^{1}$ Đặng Thị Xuân², Phan Thị Lan Hương ${ }^{2}$, Phùng Nam Lâm ${ }^{3}$

viện Bạch Mai từ tháng 01/2019 đễn tháng 7/2020. Thang điểm gồm các thông số điểm Glasgow, nhịp tim, nhip thở, $\mathrm{pH}$ máu và chỉ số $\mathrm{P} / \mathrm{F}$. Cao nhất là 27 điểm và thấp nhất 0 điểm được thu thập tại thời điểm trước thở máy và sau 3 giờ TMKXN. Khi bênh nhân phải đặt ống NKQ thì TMKXN được coi là thất bại. Kết quả: Nghiên cứu trên 71 bệnh nhân đợt cấp CÖPD có chỉ định TMKXN cho thấy tỷ lệ thất bại TMKXN là $22,5 \%$ được chia thành 2 nhóm thất bại trước 3 giờ và sau 3 giờ thở máy. Tại thời điềm trước thở máy, thang điểm HACOR có khả năng dự đoán tốt thất bại sớm của TMKXN với chỉ số AUC là 0,82 , cho thấy khả năng dự đoán tốt về thất bại của TMKXN. Sử dụng điểm cutoff là 5, độ nhạy, độ đặc hiệu, giá trị tiên đoán dương tính, giá trị dự đoán âm tính chẩn đoán thất bai TMKXN tương ứng là $75 ; 80,9 ; 79$ và $70,1 \%$. Ở những bệnh nhân TMKXN thất bại sau 3 giờ, HACOR có khả nằng dự đoán trung bình với $A U C$ là 0,77 . Với 